\title{
lon-exchange resin anticoagulation: experimental data of a novel extracorporeal regional anticoagulation technique
}

\author{
A Zanella ${ }^{1 *}$, V Scaravilli ${ }^{1}$, M Giani ${ }^{1}$, F Magni ${ }^{1}$, D Ceriani ${ }^{1}$, S Sosio ${ }^{1}$, S Spina ${ }^{1}$, C Ferrari ${ }^{1}$, S Colombo ${ }^{1}$, A Pesenti ${ }^{1,2}$ \\ From ESICM LIVES 2015 \\ Berlin, Germany. 3-7 October 2015
}

\begin{abstract}
Introduction
Regional anticoagulation has been introduced to avoid the complications of systemic anticoagulation. The most diffuse technique for regional anticoagulation is the infusion of citrate, which exerts its anticoagulative effect by chelating calcium, an essential factor of coagulation. Despite being a "regional" anticoagulation technique, a major fraction of the infused citrate reaches the patient systemic circulation and may cause toxicity. For this reason this technique can be applied only to extracorporeal blood flows lower than $\sim 150-180 \mathrm{ml} / \mathrm{min}$, to limit the amount of infused citrate. Ion exchange resins are polymers which contain acidic or basic functional groups able to exchange counter-ions. We have developed a regional anticoagulation technique featuring a cation exchange resin, which exchanges calcium with sodium and thus reduces plasmatic calcium levels.
\end{abstract}

\section{Objectives}

To investigate the feasibility and efficacy of an innovative regional blood anticoagulation technique based on cation exchange resins.

\section{Methods}

Eight healthy swine $(48.5 \pm 4.5 \mathrm{~kg})$ were sedated, intubated, mechanically ventilated and connected to a custommade veno-venous extracorporeal system featuring a cartridge containing a cation-exchange resin. Blood flow was set at $150 \mathrm{ml} / \mathrm{min}$. Systemic anticoagulation with unfractioned heparin was started and maintained for the whole experiment. During the experiment blood was sampled along the extracorporeal system before and after the resin

${ }^{1}$ Università degli Studi di Milano Bicocca, Monza, Italy

Full list of author information is available at the end of the article anticoagulation treatment to measure ionized calcium and to perform thromboelastography (TEG). The heparinasekaolin thromboelastography (HK-TEG) technique was used to evaluate coagulation, regardless of the level of systemic anticoagulation. Systemic ionized calcium and sodium levels were maintained stable by infusing a custom-made sodium-free calcium replacement solution. Three samples were withdrawn after 2, 4 and 6 hours of ion-exchange resin anticoagulation treatment.

\section{Results}

Table 1 shows the ionized calcium levels and the TEG parameters of blood along the extracorporeal circuit, before (Blood IN) and after (Blood OUT) the ionexchange resin anticoagulation treatment. The treatment was able to reduce ionized calcium levels to $0.25 \pm 0.03$ $\mathrm{mmol} / \mathrm{L}$, resulting in no sign of clot formation in samples withdrawn from the blood outlet. Systemic electrolytes were stable during the whole experiment. No adverse event ascribable to the treatment was recorded.

\section{Conclusions}

The ion-exchange resin anticoagulation technique proved to be effective to anticoagulate extracorporeal blood. Future experimental studies are required to evaluate the

Table 1

\begin{tabular}{lllc}
\hline & Blood IN & Blood OUT & p-value \\
\hline lonized Calcium $(\mathrm{mmol} / \mathrm{L})$ & $1.29 \pm 0.06$ & $0.25 \pm 0.03$ & $<0.001$ \\
\hline HK-TEG - R (sec) & $6.8 \pm 2.2$ & $>60$ & $<0.001$ \\
\hline HK-TEG - $\alpha$ Angle $\left(^{\circ}\right)$ & $2.2 \pm 0.7$ & $0 \pm 0$ & $<0.001$ \\
\hline HK-TEG - K (min) & $62 \pm 7$ & $0 \pm 0$ & $<0.001$ \\
\hline HK-TEG - MA (mm) & $66 \pm 5$ & $0 \pm 0$ & $<0.001$ \\
\hline
\end{tabular}


long-term feasibility and safety of the technique. This technique can potentially be applied to a higher range of blood flows, extending the applicability of regional anticoagulation to other extracorporeal treatment, such as extracorporeal $\mathrm{CO}_{2}$ removal.

\section{Authors' details}

${ }^{1}$ Università degli Studi di Milano Bicocca, Monza, Italy. ${ }^{2}$ Ospedale San

Gerardo, Monza, Italy.

Published: 1 October 2015

doi:10.1186/2197-425X-3-S1-A807

Cite this article as: Zanella et al:: lon-exchange resin anticoagulation: experimental data of a novel extracorporeal regional anticoagulation technique. Intensive Care Medicine Experimental 2015 3(Suppl 1):A807.

\section{Submit your manuscript to a SpringerOpen ${ }^{\mathcal{O}}$ journal and benefit from:}

- Convenient online submission

- Rigorous peer review

- Immediate publication on acceptance

- Open access: articles freely available online

- High visibility within the field

- Retaining the copyright to your article 